\title{
Urgences
}

\section{L'enfant qui n'était pas plagiaire}

\section{Simon Harel}

Numéro 29, octobre 1990

Éclats d'œuvre

URI : https://id.erudit.org/iderudit/025599ar

DOI : https://doi.org/10.7202/025599ar

Aller au sommaire du numéro

Éditeur(s)

Urgences

ISSN

0226-9554 (imprimé)

1927-3924 (numérique)

Découvrir la revue

Citer ce document

Harel, S. (1990). L'enfant qui n'était pas plagiaire. Urgences, (29), 30-35.

https://doi.org/10.7202/025599ar d'utilisation que vous pouvez consulter en ligne.

https://apropos.erudit.org/fr/usagers/politique-dutilisation/ 


\section{L'enfant qui n'était pas plagiaire Simon Harel}

Père, je ne t'ai pas volé ni ton âme, ni ton corps, ni tes pensées. Je ne suis pas l'enfant volé. Je ne suis pas l'enfant plagiaire.

Écrire? Une histoire de propriété, de jalousie, de délimitation. Pour certains, oui. Qui n'y échappe par moments. Écrire de la théorie ou de la fiction? Peu importe lorsque l'œuvre suit son cours. Il n'y a pas fondamentalement de différence quand on sait qui loge sous ce "je" qui me sollicite constamment dès que je pense... Écrire sans doute parce que je me crois digne d'intérêt, susceptible de transmettre une pensée originale? Quelle prétention! Illusion tenace d'un comblement narcissique où la pensée psychanalytique inscrit l'hallucination primitive de l'objet de désir. Écrire pour être aimé ou détester père et mère? Écrire pour séparer ce couple monstrueux qui m'a créé? Ce serait encore l'écriture du jaloux, de l'enfant qui veut avoir tout l'amour dont il pourrait rêver. Ecrire? Une propriété privée de l'ỉmaginaire. Certainement pas. Un compte à rendre. Mais ce serait bien triste, une écriture soumise au tourment de la dette à respecter, du tiers exclu, de la rançon payée au nom de ce que l'on appelle le savoir.

Tu es un père fragile - loin de tout

Et la tendresse s'effiloche telle une lame mal tendue, vers mon cœur et la certitude d'une distance, contraignante.

C'est la fin pensais-je et pourtant le temps passe. Je rêve de ta mort imagée.

Mais il reste cette bouée faite de pleurs maritimes, de terre qui s'effrite, de douleur à revivre et une parole qui s'abrège.

Je ne peux pas mourir de ta mort et tu ne peux disparaître. Fais-en le serment. 
Au lien du tien. Tissé de cette lame qui abrège le sang versé en souvenir de l'amour du fils.

C'est un rêve as-tu dit, un mauvais rêve. Oui! À la peur intense correspond la plus grande des jouissances. Quelle joie de t'avoir perdu pour ce court instant et de reconnaître le temps à venir.

L'enfant a dix ans. Il écrit. Les idées peuvent-elles suivre leur cours - pensées navigantes comme les fumées de paquebots qu'il observe de la rive.

C'est seulement plus tard que cette pensée lui viendra à l'esprit, ce qu'on appelle, lorsqu'on a dix ans, être âgé. Pensées étranges qui semblent obsédantes et douloureuses parce qu'elles surgissent d'un obscur désir de retour à une origine à jamais perdue. Et ces pensées sont trompeuses parce qu'elles s'entêtent à raccourcir le temps, à l'éventrer comme si demain et aujourd'hui n'avaient plus de sens.

Lui, adulte, vivant, c'est l'enfance qui le pourchasse et le laisse esseulé dans la quête du regard. Je ne suis pas l'enfant tué mais seulement l'enfant silencieux et regardant, ancré dans Pimpossible fusion avec la vie et redoutant d'en savoir trop.

Écrire une œuvre afin de pouvoir composer à ma guise une enfance perdue.

Chercher dès que la tentation m'en est offerte un lieu (surface incarnée) qui condense, en son sein, fragmentation et unité. Lieu redécouvert de l'enfance analogue au scénarioécran (un alibi?) qu'est pour l'auteur que je suis cet enfant plagiaire.

J'imagine que le «je " du créateur est toujours de circonstance. Écrire?... une fabulation, une reconstruction mémorielle. Doit-on conclure à une falsification dès que l'on se met à traduire "en mots " ce qu'est l'acte d'écrire. Je préfêre plutôt y voir ce que l'on nomme en psychanalyse une mouvement de perlaboration. Il n'y a ceuvre que dans l'aprèscoup qui, fantasmatiquement, détermine ce que l'on voudrait avoir écrit, ce que l'on souhaiterait avoir été. Temporalité créatrice qui conjugue "l'être * et «l'avoir*: le désir d'une création à laquelle seraient associées des valeurs d'omnipotence, de complétude narcissique; et le constat implacable de l'ananké qu'est pour le créateur ce qu'il offrira au lecteur imaginaire lorsqu'il aura enfin complété son œuvre. 
L'œuvre à créer?... imbrication d'une temporalité (un «faire " qui est projection, mise en retrait du désir dans l'élaboration même du projet créateur) et d'une forme: espace qui est configuration gestuelle, corporelle. Somme toute, interrogation interminable sur l'élaboration d'une limite de la pensée.

Il a peur, il redoute, il craint. L'autre jour, chez lui, il a cherché dans le dictionnaire la définition du mot «épouvante", du mot « frayeur *, du mot * effroi » croyant peut-être y trouver une réponse, l'indication d'une douleur qui l'aurait traversé.

Mais on n'a pas peur comme ça sans raison. La frayeur, tu le sais, est le comble du désir. "Écoute père" se dit-il alors "pourquoi me laisses-tu dans la hantise de ne pas savoir aimer... pourquoi nous retrouvons-nous aujourd'hui si malheureux, empêtrés dans nos duretés - pacotilles qui viennent du désir soudain d'évacuer la mort. Écoute père, écoute-moi s'il te plait, ne pars pas comme un voleur, ne t'esquive pas, ne m'accuse pas de ma trop grande fragilité. Les mots viennent lentement. Doucement ils commencent à sortir d'une très longue nuit. La veilleuse est là. C'est ma chambre tout petit et je ne m'endors pas ou c'est le phare sur le fleuve et je ne veux pas que tu te noies. Écoute père, viens vers moi. Ne crains pas. Ton fils ne voudra pas se venger. Les enfants sont fragiles. Ils sont déracinés et ça ne sert à rien, ça ne servira jamais à rien. "

Je ne peux écrire sans désir de connaître. L'enfant plagiaire, c'est le lot des adultes que nous sommes. Enfant qui fut confronté, lors d'une scène - réelle ou fantasmatique qu'il n'oubliera jamais, à l'accusation de ne pas avoir été la source de sa pensée. D'avoir démérité ce qui le constitue comme sujet imageant. Sentence dramatique - dont la résonance, quant à la singularité de nos pensées, forge bien des systèmes théoriques paranoïaques qui se caractérisent par leur fermeture - qu'on pourrait énoncer ainsi : "Tu n'as pas écrit (pensé) ce que je lis, ce que j'entends. » 
Tu te caches sous les frondaisons tel cet amant malheureux et tu marches.

C'est encore la même image qui revient, douloureuse et puis tendre d'un cours d'eau asséché, ocre, semblable à la terre dont la peau de nos membres n'est que la fine transparence. Jusqu'au moment où tout cela, fatigué par le feulement du temps, laissera place à l'épuisement de la matière, ce mot qui dit la vie des corps, à l'abri, protégé dans le sanctuaire de l'oubli.

Mais où es-tu à ce moment de peur, d'effroi statique, car je vais tomber, je sais que la peur distille sa terrible insuffisance. Je ne la supporte plus... Ma propre peur est celle de mourir avec toi dans tes bras, étouffé par ce si grand amour des corps qui s'étreignent quand ils tombent dans le vide. Et pourtant, ensemble, nous ignorerons enfin le temps et la gravité, nous ne marcherons plus, nous ne saisirons plus les choses, nous ne prendrons plus rien qui ne soit définitif. T'étreindre et retourner en ton sein.

"Tu ne veux pas ma mort", dis-tu. Il y a ce qui échappe à l'image et qui ne mène qu'à une route déjà parcourue. Tu es mon père-baleine, branchies flétries doucement par le sel marin. Tu es l'écho de ma voix distendue sur les rochers des plaines maritimes. $\grave{A}$ entendre l'incessant appel de ton corps qui plonge dans les profondeurs, et moi ébahi par la rumeur de tout cela. À distance, toujours en retrait, voyant ton corps plonger et replonger à l'appel et moi l'enfant non accompagnateur, seul sur la rive, désceuvré de ma paternité, à la recherche du père-orque, cachalot et algues séchées des comptines quand on revient sur la terre. Père de l'appel et du phare, de la distance sans retour, si tu m'avais perdu, il faudrait que je t'accompagne à nouveau cette fois avant de te quérir.

Jugement terrifiant d'un père, d'une mère, d'un aîné ou d'un maître. Pouvoir créer consiste sans doute, selon les aléas de nos histoires personnelles, à occuper un tant soit peu la position de cet enfant imaginaire qui s'est senti dépossédé de ses pensées. À quitter le registre paranoïaque qui est la conséquence directe de cette accusation de plagiat: « Puisque lui m'accuse d'être un autre - de ne pas être responsable de mes pensées - je ne cesserai de revendiquer 
34

la singularité de mon œuvre. "Seule la mise à distance de la paranoïa, toujours homogène, territoriale, et jalouse, permet la création: art impropre, constamment partagé, (re)connaissance de filiations, métissage.

Cet enfant est un voleur de mots. C'est ce qui a été dit le jour où il est venu au monde. Il avait respiré tranquillement de nombreuses heures sous l'éclairage des néons de la pouponnière et son père avait dit qu'il était un voleur de mots. Et il lui vint beaucoup plus tard à l'esprit qu'il avait connu prématurément le secret du vol et de l'oubli, la persistance du désir de savoir et ce qui en limite toujours l'achèvement. Voler des mots, c'était peut-être un peu prématuré et il était né par césarienne: un enfant ouvrant le ventre de sa mère, apparaissant brutalement à la lumière.

Tout jeune il n'a cessé de se poser une question. Comment lui l'enfant s'était-il attribué, reprenant à son compte la légende paternelle, le nom de voleur de mots? Pourquoi était-il devenu ce fugueur en manque d'espace?

C'est toi petit père de tous les amours, de toutes les solitudes. C'est toi logé dans cette cage sonore qui t'enferre et te possède. Á genoux, déjà éprouvé par celui qui te conduit vers ton propre dépassement.

Le fils est fils du père

Il n'en est ni le signet ni l'entrée en matière

C'est un être. Chair et os. Filaments et tendresse des veinules - cette peau est une rosace tendue.

Le père ne sait rien du fils. De l'amour ou de la désillusion comme traité fastidieux de lucidité.

Il n'a rien à savoir de son fils.

Père protecteur. À te replier pour porter, tu t'es fait mal - l'armure était cette peau que je ne peux pas voir vieillir. 
Or il n'y a pas de temps révolu. Père et fils cheminent dans leurs généalogies respectives.

En somme il fallait, père, que tu sois en retrait pour que jintervienne. Tous les mots que tu m'avais appris, les livres d'images et les souvenirs des rêveries que tu me contais, il fallait que je puisse te les rendre un jour.

L'enfant voleur de mots est un lecteur d'atlas. 